\title{
DIRECTIONALLY SOLIDIFIED MATERIALS: NICKEL-BASE SUPERALLOYS FOR GAS TURBINES $\dagger$
}

\author{
JACQUES LACAZE and ALAIN HAZOTTE \\ Laboratoire de Science et Génie des Matériaux Métalliques, Ecole des Mines, \\ 54042 Nancy cédex, France
}

(Received 20 December 1989)

From the first forged turbine blades made of iron base alloys to the present nickel base single-grain turbine blades and vanes manufactured by directional solidification, an enormous amount of research has been directed to attaining the hottest possible combustion chamber temperatures in jet engines. Temperature has been increased by about $15 \mathrm{~K}$ each year for the last two decades, improving the thermodynamic efficiency of the engines. The more recent developments concern the manufacturing of single-grain parts made of nickel base superalloys with large amount of the $\gamma^{\prime}$ hardening phase.

This paper first presents the directional solidification process used to produce single-grain parts, the formation of as-cast microstructures and the defects that can arise during solidification. In the second part the thermal treatments that are applied to the nickel base superalloys in order to enhance their mechanical properties are detailed. The effect of crystallographic orientation and of the $\gamma / \gamma^{\prime}$ microstructure on the mechanical properties is briefly presented, as well as the microstructural changes that can possibly arise during service.

KEY WORDS Directional solidification, nickel base superalloys, microstructures, high temperature mechanical properties.

\section{INTRODUCTION}

In order to improve the efficiency of jet engines, an enormous amount of research has been directed to increasing the temperature of the gas coming from the combustion chamber and entering the turbine (the turbine inlet temperature). As illustrated in Figure 1, this temperature has increased by about $15 \mathrm{~K}$ each year for the last two decades, leading to an improvement of thrust for military engines or a reduction of fuel consumption in the case of civil engines. Thus the main requirements for materials used in gas turbines are determined by the temperature capabilities of the rotating blades, their creep resistance at high temperature, good resistance to thermal fatigue and to oxidation/corrosion. According to McLean (1983), a practical rule states that one third of the total damage undergone by the material is due to fatigue and two thirds to creep.

The main process changes and alloy developments that led to the improvement in turbine capabilities are schematized in Figure 1. Between the forties and the sixties, wrought alloys changed from Fe-base to Ni-base alloys as the introduction of nickel with aluminum and titanium led to the formation of $\gamma^{\prime}$ precipitates,

$\dagger$ This paper was presented at the COMETT Symposium "Anisotropic and Microheterogeneous Materials", Metz, France, December 1989. 


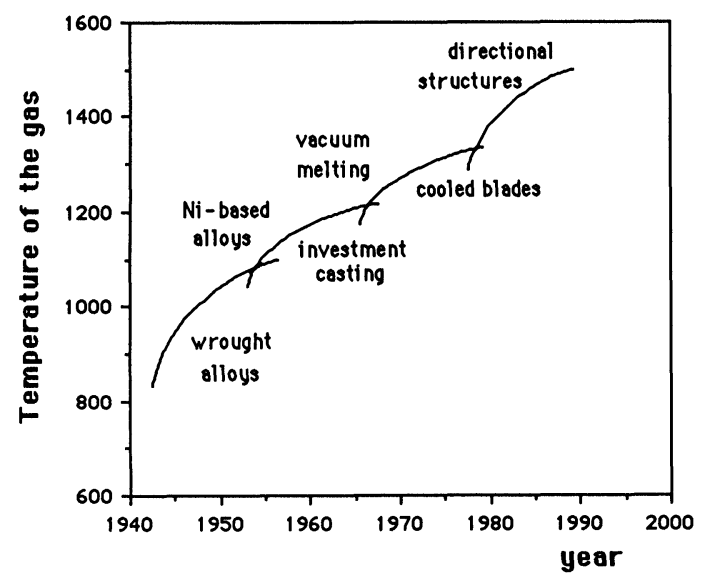

Figure 1 Evolution of the gas temperature at the entry of turbines (turbine inlet temperature) during the last decades, related to successive changes in the processes.

isomorphic to the $\mathrm{Ni}_{3} \mathrm{Al}$ phase, which increase the creep resistance of the materials. Modern alloys for high temperature airfoils do not contain any iron at all but are composed of nickel with a number of alloying elements that have different roles; $\mathrm{Al}, \mathrm{Ta}, \mathrm{Ti}$ and $\mathrm{Nb}$ enter in the $\gamma^{\prime}$ phase and increase the quantity of precipitates; $\mathrm{W}, \mathrm{Cr}$ or Mo are added as $\gamma$ solid-solution strengtheners and increase the amount of carbide, if any; Co increases the high temperature stability of the precipitates. The introduction of the vacuum melting technique in the sixties allowed casting of alloys with larger amounts of reactive elements such as aluminum and titanium. The amount of the strengthening phase became so high that forging was no longer possible since the temperature interval for thermomechanical treatments was situated at a higher temperature; this led to the use of investment casting for manufacturing airfoils.

IN100 or MARM200 (see Table 1) are typical alloys developed in the 60's for manufacturing turbine blades with equiaxed structures by conventional casting in molds achieved by the lost wax process. These alloys, which are still in use for sub-critical parts of the engines, contain about $40 \% \gamma^{\prime}$ and 5\% carbides. The $\gamma^{\prime}$ phase precipitates in the $\gamma(\mathrm{Ni})$ matrix and hardens it when the carbides are intergranular and increases the resistance of the grain boundaries. Boron, hafnium and zirconium are added in order to reduce crack initiation at grain boundaries. The optimum efficiency of the carbides as grain boundary strengtheners is obtained after appropriate heat treatment (Sims, 1978).

A further improvement of the materials was achieved by considering the actual

Table 1 Composition (in wt\%) of some nickel base superalloys

\begin{tabular}{llcrllllllll}
\hline & $A l$ & $C o$ & $C r$ & $M o$ & $T a$ & $T i$ & $W$ & $B$ & $C$ & $V$ & $Z r$ \\
\hline IN100 & 5.5 & 15 & 10 & 3.0 & - & 4.7 & - & 0.014 & 0.18 & 1.0 & 0.06 \\
MAR M200 & 5 & 10 & 9 & - & - & 2.0 & 12.5 & 0.015 & 0.14 & - & 0.05 \\
PWA 1480 & 5 & 5 & 10 & - & 12 & 1.5 & 4 & - & - & - & - \\
CM SX2 & 5.5 & 5 & 8 & 0.5 & 6 & 1 & 8 & - & - & - & - \\
AM1 & 5.2 & 6.5 & 7.5 & 2.0 & 8.5 & 1.2 & 5.5 & - & - & - & - \\
\hline
\end{tabular}

Note: for D.S. applications, MAR M200 alloy also contains $1 \% \mathrm{Nb}$ and $2 \% \mathrm{Hf}$ 
demands made of airfoils. It was first noted that for materials with equiaxed structures, creep fractures and thermal fatigue failures were always associated with grain boundaries. As service stresses are mainly due to centrifugal acceleration along the airfoil direction, it became obvious that directional structures could increase the mechanical properties of the blades in service by suppressing the transverse grain boundaries which were the weakest points; this has been achieved by using directional solidification (D.S.) to produce the material. The advantages of these structures over conventional equiaxed structures was an increase of the thermal fatigue capability and of the rupture life and ductility (VerSnyder, 1982). Finally the introduction during the 70's of cooled blades allowed a further increase in the engine thrust. Cooling with cold air taken from the compressor allowed for a temperature difference between gas and metal that can be as high as $500^{\circ} \mathrm{C}$ in the modern engines.

The present last step of the evolution has been the introduction of single grain manufacturing of airfoils which led to a drastic change of the definition of the alloys, as elements acting as grain boundaries strengtheners $(\mathrm{C}, \mathrm{B}, \mathrm{Zr}, \mathrm{Hf})$ could be eliminated. Recently designed alloys such as AM1, CMSX2 or PWA 1480 (Table 1), have important advantages over previous alloys. Their incipient melting temperature as well as their solvus temperature are increased, thus increasing their performance, and yet these temperatures are still sufficiently different to allow full solutionizing heat treatments that were not possible in the case of alloys of the first generation.

\section{CASTING OF SINGLE-GRAIN PARTS}

\section{Practice of Directional Solidification of Nickel-base Alloys}

Conventional or directional solidification of modern nickel based superalloys is achieved by investment casting using the lost wax process. This process, which has been in use for art manufacturing for several thousand years, is a convenient way to realise near net-shape casting with austenitic and refractory steels and nickel and cobalt based superalloys as well as light alloys (Zanghi, 1988). In this technique the mold is prepared from a preform made of wax on which successive layers of ceramics are deposited. After drying the mold is dewaxed and then heat treated.

The thermal and mechanical characteristics of the mold shell must be compatible with the casting process. First of all the ceramics have to retain sufficient high temperature mechanical properties as the mold is subjected to creep due to the weight of the metal. Secondly the inner ceramic layers must be chemically resistant to the liquid metal for a sufficiently long time in order to avoid compositional changes of the metal and deleterious additions of exogeneous particles. These problems became evident as the casting time was increased when the D.S. process was introduced. Finally the thermal conductivity and the heat capacity of the mold must be carefully chosen as it is necessary for the D.S. process to ensure that the liquidus isotherm is planar. Alumina based ceramics are generally used because they present both satisfactory mechanical characteristics and good thermal conductivity.

As pointed out in the introduction, one of the major increases in turbine inlet temperature was due to the development of air cooled blades and vanes. The corresponding shapes are achieved by means of ceramic cores inserted in the wax 


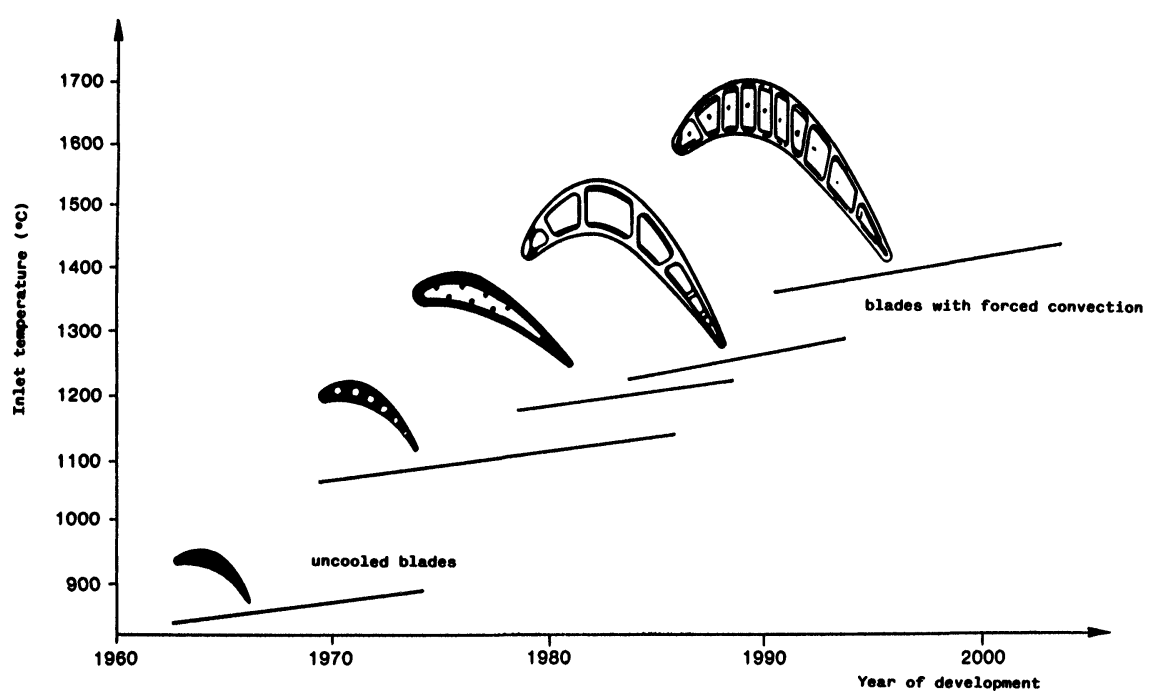

Figure 2 Schematic representation of blade sections illustrating the evolution of the cooling ducts. (After Herteman, 1985)

pattern and that remain in place in the mold during the solidification process. These cores, which can be silica or alumina based, are later removed from the parts by dissolving them in acid. The possibilities of this technique were so great that a progressive new design of the blades was achieved, from the simple hollow to the very complex air circulating circuits illustrated in Figure 2. In future turbine blades, air cooling will be ensured through forced convection and turbulent flow inside the blades and through a cooling film on the exposed outer surface of the blades.

In the case of the directional solidification process it is particularly important to avoid the possible nucleation of new grains on the mold surface, essentially due to undercooling of the liquid metal ahead of the solidification front. One way to avoid this undesirable phenomenon is to increase the temperature gradient at the solidification front; this idea led to the development of heated furnaces in place of the simpler liquid cooling process (Figure 3 ). These furnaces have two chambers, a cold and a hot one. The alloy is melted under vacuum in a pouring cup in the hot chamber and then poured in the mold which was first preheated $\left(1100^{\circ} \mathrm{C}\right)$ and degassed in the "cold" chamber. The mold stands on a cooled copper chill surface on which solidification starts and is then withdrawn from the furnace. When single grain parts are to be manufactured, there is a grain selector in the lower part of the mold.

\section{Formation of the Directional Solidification Structures}

The actual solidification structures of an alloy depend on the processing parameters, primarily the temperature gradient $G$ at the solidification front and the solidification rate $V$, which is roughly equal to the withdrawal rate. For a given thermal gradient the increase in the withdrawal rate from very low to very high values makes the solidification front change from planar to cellular, 


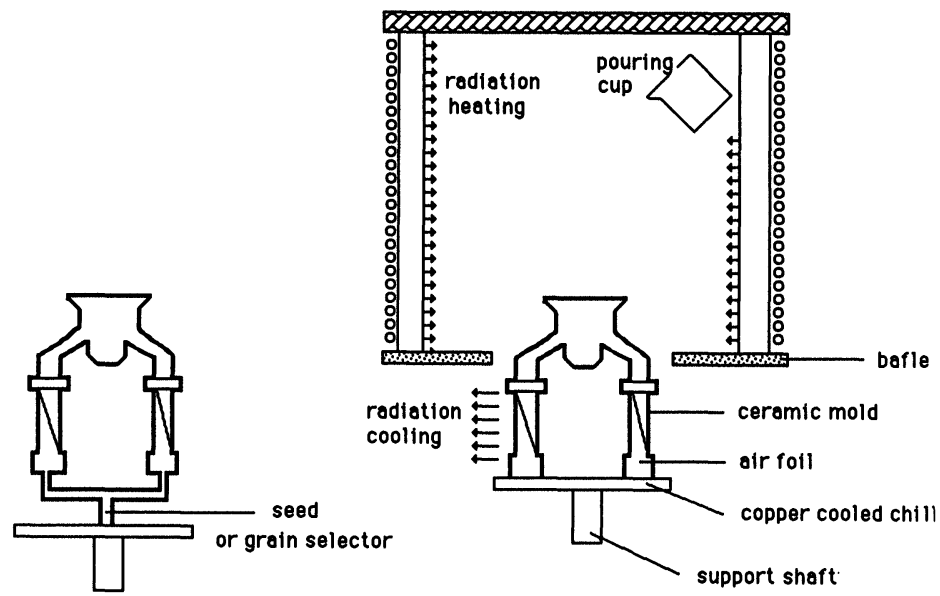

Figure 3 Schematic view of the hot chamber of a D.S. furnace with the mould standing on cooled copper support.

columnar (or directional) dendritic and finally equiaxed dendritic as illustrated on Figure 4. In the industrial D.S. process the thermal gradient is in the range 20 to $60 \mathrm{~K} \mathrm{~cm}^{-1}$ and, for productivity reasons, the solidification rate is the highest possible, typically 4 to $10 \mathrm{~mm}$ per minute. Columnar dendritic structures are formed of primary trunks whose tips grow ahead in the liquid and develop transversely through the formation of secondary arms as illustrated in Figure 5. Dendrites grow preferentially in the crystallographic [001] direction and their arms in the two perpendicular $\langle 001\rangle$ directions. In nickel base superalloys these crystallographic directions are associated with low elastic moduli. This ensures better thermal fatigue resistance as the level of thermal strains remains low.

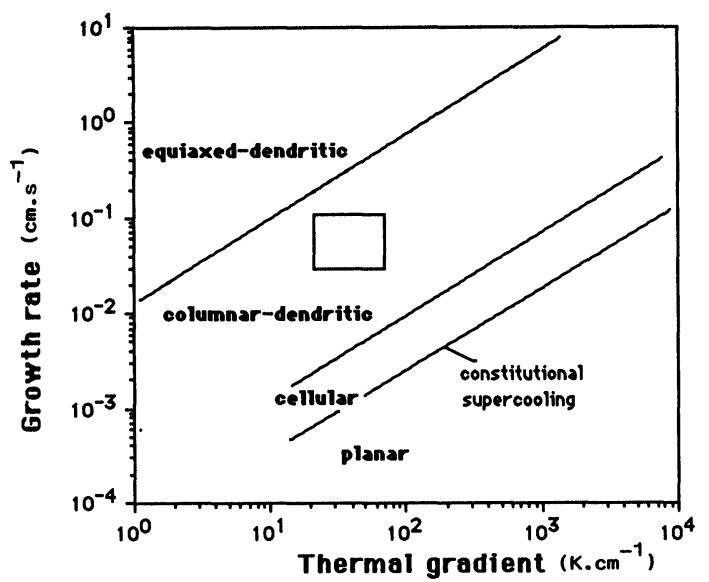

Figure 4 Effect of the thermal gradient $G$ and the solidification rate $V$ on the type of solidification structures that develop. The square represents the domain in which it is industrially possible to achieve the D.S. process. 


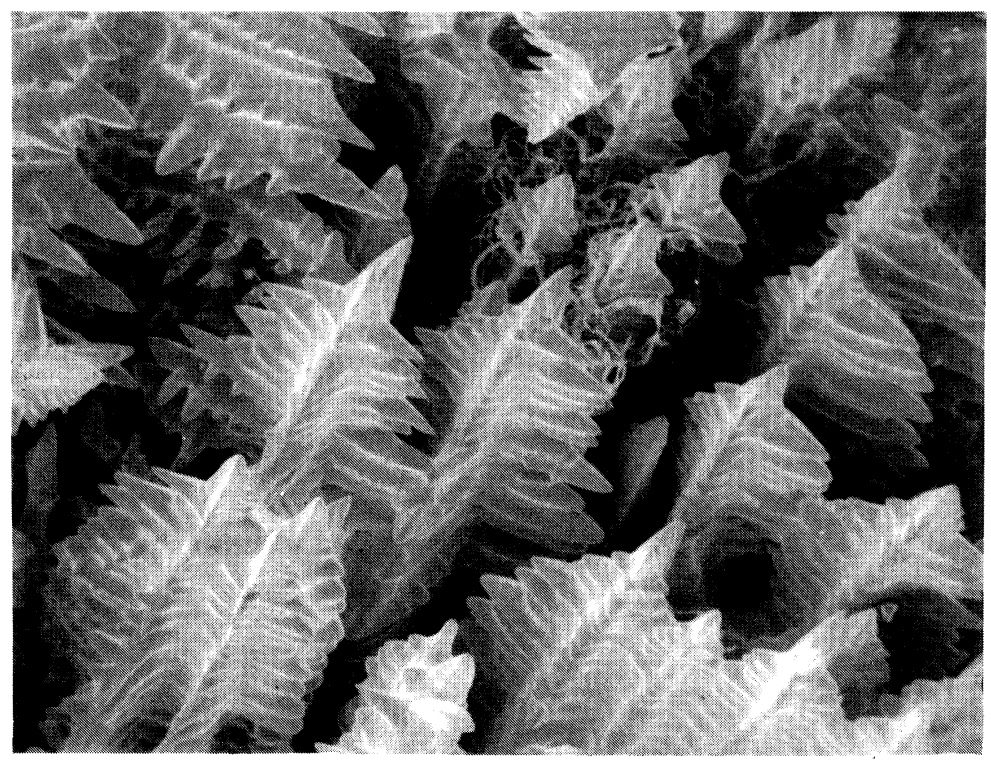

Figure 5 SEM photograph of an array of growing columnar dendrites (by courtesy of E. Gardaix). Average distance between dendrite trunks is $350 \mu \mathrm{m}$.

Due to the cooling rates undergone by the metal during the phase change, solidification proceeds off-equilibrium and leads to local chemical heterogeneities called microsegregation. Microsegregation is caused by solutes partitioning between liquid and solid at the scale of the dendrites or dendrites arms. During solidification the composition of the liquid varies continuously as does that of the successive layers of solid. Since the solid state diffusion rate is low with respect to the usual cooling rates, this leads to the build-up of microsegregation and to the final precipitation of off-equilibrium $\gamma-\gamma^{\prime}$ eutectic. Near the end of solidification however, some solid state diffusion can occur for the faster diffusing elements as aluminum.

The main consequences of microsegregation are illustrated in the micrographs of Figure 6 that were taken on polished and chemically etched sections parallel to the growth direction: the chemical heterogeneity of the as-cast material (left) and the common appearance of off-equilibrium phases, like the $\gamma^{\prime}$ phase in the $\gamma-\gamma^{\prime}$ eutectic (right). The formation of macrosegregation, that is chemical heterogeneities at the scale of the cast parts, is associated with both microsegregation and cross-sectional area changes (Sellamuthu, Brody and Giamei, 1986). This is to be avoided as it is a major defect detrimental to mechanical properties which cannot be eliminated through usual heat treatments.

In general solid-state $\gamma^{\prime}$ precipitation begins just after the end of solidification during the casting process. This is a great advantage of the new generation alloys in that they present a temperature "window", that is a temperature interval between the solvus temperature and the incipient melting temperature, in which full solutionizing of the $\gamma^{\prime}$ precipitates and chemical homogenization are possible. The efficiency of the heat treatments is related to the dimensions over which chemical heterogeneities have built up. These dimensions are those of the 

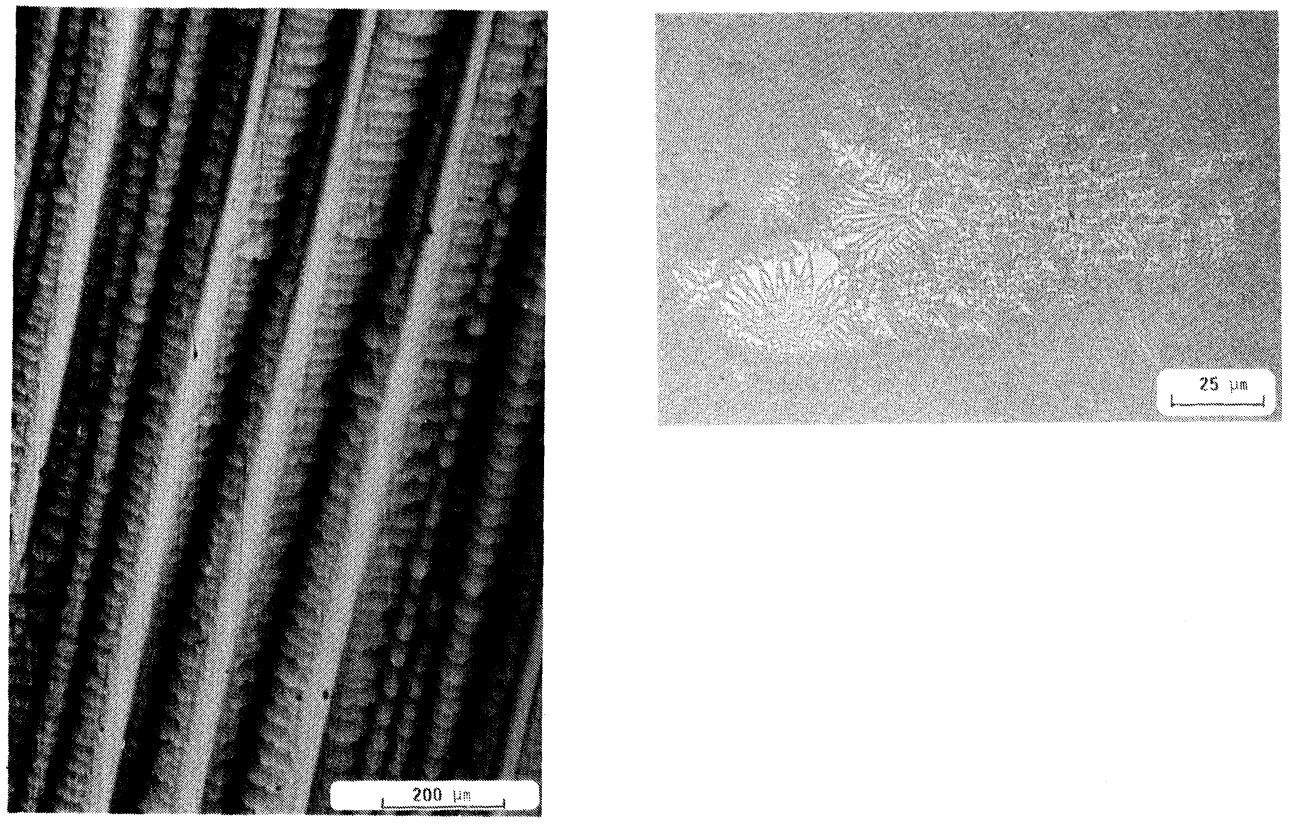

Figure 6 Micrographs of longitudinal sections (parallel to the growth direction) illustrating chemical heterogeneities, microsegregation at the scale of the dendrites (a) and off-equilibrium $\gamma-\gamma^{\prime}$ eutectic (b) in as-cast material.

dendritic structure, the average distance between dendrite axes and the secondary and occasionally the tertiary arms spacings (Flemings, 1974). A convenient way for estimating the size of a dendritic array like the one shown in Figure 7, is to measure the density of primary axes $n_{p}$ (Lacaze, 1987), which varies with the solidification parameters $G$ and $V$ according to a relation of the form $n_{p}=$ $A \cdot G \cdot V^{0.5}$.

$A$ depends on alloy composition but also on the solidification conditions (Kurz and Fisher, 1983), and this can account for the large discrepancies concerning the experimental values of the exponents of $G$ and $V$ reported in the literature. One of the reasons for the variations of $A$ is tip undercooling at the solidification front that causes the actual solidification interval to vary. This tip undercooling is due to solute redistribution around the dendrite tips when growing. It varies essentially with $V$ but can also depend on the temperature gradient when the gradient is large. The undercooling exists in a zone in the liquid, ahead of the solidification front, which has a liquidus temperature lower than the nominal liquidus temperature of the alloy. In this zone, nucleation of new crystals is theoretically possible and their effective growth will depend on the undercooling of the front and on the temperature gradient in the liquid. This explains the transition from columnar to equiaxed growth illustrated in Figure 5. There exists a maximum withdrawal rate for D.S. manufacturing as the risk for nucleation of new grains above the solidification front increases with the tip undercooling.

As pointed out above the progress of solidification behind the front is associated with the formation of dendrite arms initiated as perturbations of the dendrite tips. 


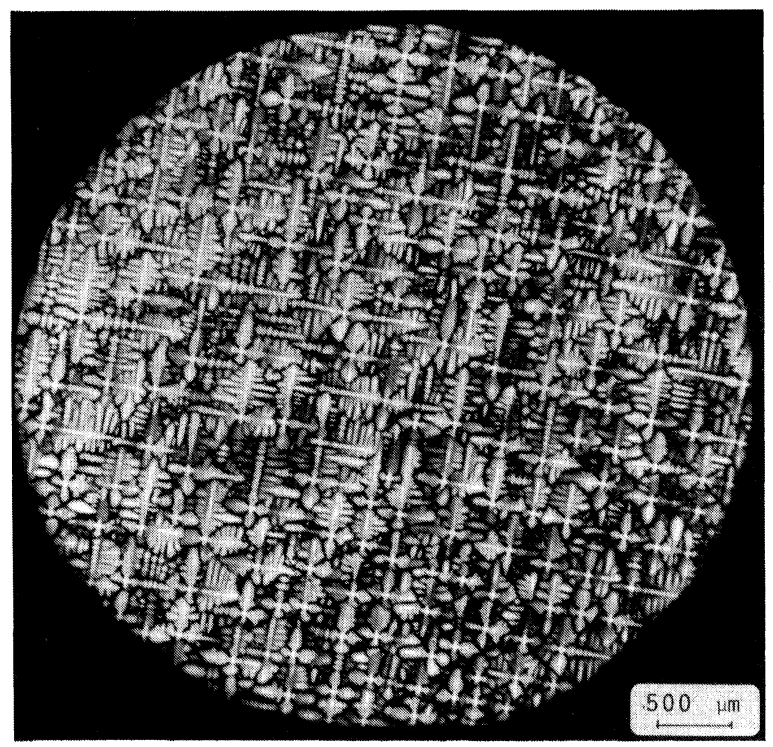

Figure 7 Micrograph of a transverse section of a single grain showing the array of dendrites which appear as white crosses.

It has been shown (Flemings, 1974) that the final size $d$ of these arms depends on the local cooling rate of the metal and is determined by coarsening, so that one has:

$$
d^{3}=a \cdot t_{\text {sol }}
$$

where $a$ depends solely on the alloy composition and $t_{\text {sol }}$ is the local time for completion of solidification.

Another very important defect encountered in cast materials consists of cavities, either porosity or microcracks. Both of them are thought to appear at the end of solidification, the first due to a lack of liquid feeding to compensate for solidification shrinkage and the second due to stress and strain build-up as the solid part of the casting is becoming stronger. A sufficient liquid metal feeding in the last zones to solidify will lead to safe products, avoiding formation of pores and eventually healing hot tears. However capillary feeding becomes more and more difficult as solidification proceeds to its end because of the dynamic pressure drop; if the local pressure in the liquid falls below a critical value (which practically depends on the gas content of the metal) then porosity is likely to appear. The formation of pores actually depends on nucleation phenomena and on the size of the interdendritic zone; porosity will have more difficulty appearing in fine dendritic structures. However one can predict that decreasing the size of the solidification structure leads to an increase of the dynamic pressure drop, so that there must exist an optimum value of the casting conditions in order to get a minimum risk of porosity formation or to have fine evenly distributed porosities (Bachelet and Lesoult, 1978). Hafnium has been added to some D.S. superalloys to increase their castability through the increase of off-equilibrium eutectic, allowing for a decrease of the porosity tendancy and crack formation. In 
superalloys of the second generation, this type of element is avoided, but fortunately directional solidification leads to less porosity formation than conventional casting. In any case the Hot Isostatic Pressure process can be used to suppress porosities that appear during solidification or due to the thermal heat treatments described below.

\section{SOLID STATE HEAT TREATMENTS AND MECHANICAL PROPERTIES}

\section{Strengthening Mechanisms}

The high temperature properties of single crystal nickel-based superalloys essentially result from two contributions: strengthening by precipitation of the $\gamma^{\prime}$ phase and solid solution strengthening of both $\gamma$ and $\gamma^{\prime}$ phases by alloying elements. Ti, $\mathrm{Nb}$ and Ta reinforce the $\gamma^{\prime}$ phase, while $\mathrm{Cr}$, Mo and $\mathrm{W}$ act on the $\gamma$ phase. The chemistry of the successive generations of nickel base alloys evolved in order to increase these strengthening effects, especially by increasing the amount of $\gamma^{\prime}$ precipitates which has reached $70 \%$ in the last generation of superalloys. Fredholm (1987) showed that, in these alloys, the volume fraction of precipitates is roughly constant between room temperature and $1050^{\circ} \mathrm{C}$.

Figure 8 shows a typical $\gamma-\gamma^{\prime}$ microstructure of alloy CM SX2 resulting from a heat treatment which will be discussed later. Both $\gamma$ and $\gamma^{\prime}$ phases have the same f.c.c. crystallographic structure except that the $\gamma^{\prime}$ phase is ordered (" $\mathrm{L} 1_{2}$ " structure) whereas the $\gamma$ phase is a disordered solid solution. This fact, together with a difference in the distribution of the alloying elements between the two phases, results in slight difference in their lattice parameters which is often expressed by the misfit (or mismatch) parameter, given as:

$$
\delta=2\left(a^{\gamma \prime}-a^{\gamma}\right) /\left(a^{\gamma \prime}+a^{\gamma}\right)
$$

where $a^{\gamma}$ and $a^{\gamma \prime}$ are the lattice parameters of the $\gamma$ and $\gamma^{\prime}$ phases respectively.

For current industrial alloys, $\delta$ roughly ranges between $0.5 \%$ and $-0.5 \%$, depending on the temperature and on the mean chemical composition. It is generally found to be negative at service temperatures, as the thermal expansion coefficient of $\gamma^{\prime}$ is lower than that of $\gamma$.

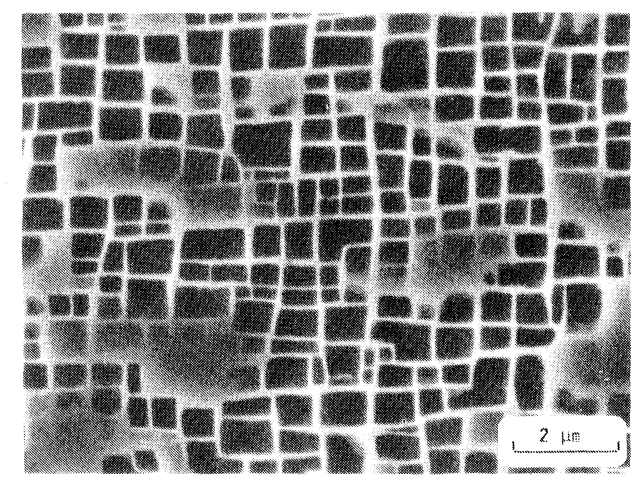

Figure 8 Typical $\gamma-\gamma^{\prime}$ microstructure of a single crystal nickel based superalloy observed on a section parallel to one of the $\{100\}$ crystallographic planes. 
Resulting from the specificity of the $\gamma-\gamma^{\prime}$ mixture, four different mechanisms are thought to contribute to the high temperature precipitation hardening of these alloys:

- as the $\gamma^{\prime}$ phase is ordered the dislocations have to dissociate in order to enter the precipitates, which results in a high shear energy,

- the $\gamma^{\prime}$ phase presents an unusual mechanical behaviour since its flow stress is known to increase with increasing temperature reaching a maximum around $700^{\circ} \mathrm{C}$ (Sims, 1972),

- the lattice discrepancy between the two phases results in strong elastic stresses at the $\gamma-\gamma^{\prime}$ interface,

- the high amount of coherent strengthening phase also results in a strong elastic interaction between precipitates; these last two phenomena both increase the difficulty of bypassing of the precipitates by dislocations gliding along the $\gamma-\gamma^{\prime}$ interface.

All these mechanisms plus solid-solution strengthening improve the mechanical properties of the single crystal alloys. However their respective contributions are not exactly quantified, even if the strengthening effect of the $\gamma-\gamma^{\prime}$ interface appears to be preponderant.

\section{Solid State Heat Treatments}

For a given chemical composition, i.e. a given amount of strengthening phase, the mechanical properties of a single crystal nickel base alloy can still be enhanced by optimizing the morphology of the $\gamma-\gamma^{\prime}$ mixture by means of appropriate heat treatments. In the case of alloy CM SX2, Caron and Khan (1983) showed that the following sequence of heat treatments (known as "ONERA treatment") leads to the best high temperature creep behaviour:

i) 3 hours at $1315^{\circ} \mathrm{C}$, then air cooled:

This temperature is in the solutionizing window, hence this step is used to dissolve the $\gamma-\gamma^{\prime}$ eutectics and to smooth the chemical segregations resulting from the casting process. Figure 9 illustrates the effect of this treatment as can be seen by optical microscopy on chemically etched structures.

(a)

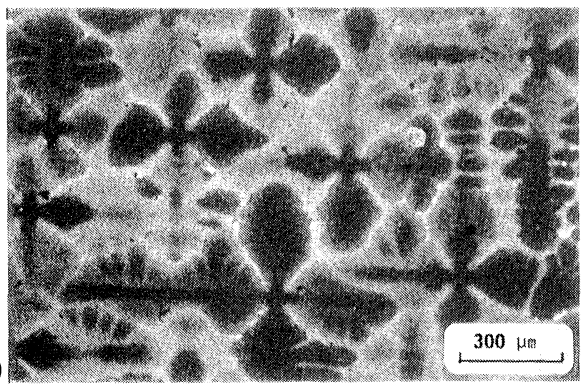

(b)

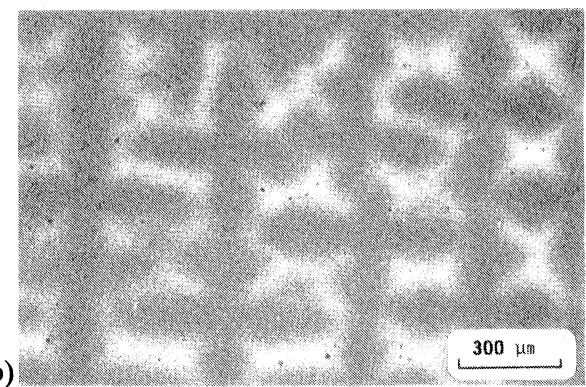

Figure 9 Effect of solutionizing treatment on microsegregation in a CMSX2 single crystal: optical micrographs showing the dendritic solidification structure (a) before and (b) after 3 hours at $1300^{\circ} \mathrm{C}$. 
ii) 16 hours at $1050^{\circ} \mathrm{C}$, air cooled:

This second treatment promotes the coarsening of the $\gamma^{\prime}$ precipitates up to their optimum size which has been experimentally determined to be $0.45 \mu \mathrm{m}$ in the case of CM SX2. This high temperature coarsening at constant volume fraction of precipitates is known as "Oswald ripening."

iii) 48 hours at $850^{\circ} \mathrm{C}$, air cooled:

The actual effects of this final "stabilization" step are not fully understood, although it was shown to be useful. It is thought to allow some retained alloying elements to migrate from the matrix into precipitates and also perhaps to modify the local chemical composition at the $\gamma-\gamma^{\prime}$ interface.

The microstructure resulting from such a heat treatment is shown in Figure 8 in the case of CM SX2 alloy. The same type of treatment has also been shown to be successfull for other single crystal superalloys. It could be surprising that the area decrease of the $\gamma-\gamma^{\prime}$ interface related to coarsening of the precipitates during the last two steps can result in strengthening of the material, while the interface was previously noted to have the main strengthening effects. In fact it is not obvious that the optimum mechanical characteristics determined experimentally correspond only to a size effect since the coarsening of the precipitates also results in a more complex microstructural evolution:

- due to the competition between their volume, interfacial and interaction energies, the precipitates encounter successive shape changes when coarsening, the usual sequence being spheroid then cuboid (see Figure 8), then platelet if the coarsening treatment is too long,

- as the mean size of the precipitates increase, their size distribution become sharper while their spatial repartition is also modified: from initially evenly distributed the precipitates progressively align along the $\langle 100\rangle$ directions; these changes, which are not forecast by the classical theories concerning Oswald ripening, are related to a minimization of the $\gamma^{\prime}-\gamma^{\prime}$ interaction energy,

- the morphological changes also correspond to a modification of the crystallographic and perhaps also chemical structure of the $\gamma-\gamma^{\prime}$ interface; for instance it is likely that the transition from cuboids to platelets is related to a progressive loss of coherency between the two phases.

The final treatment of the turbine blades before use is the application of a coating which will give them resistance to high temperature oxidation and corrosion. The coating is made of different layers specifically designed to protect against high or low temperature corrosion, high temperature oxidation and eventually completed with a thermal barrier layer. Aluminum and chromium that enter the base material play an important role against oxidation as these elements build up oxide layers. When coatings are applied by vapor phase deposition, the cycle can include heat treatments of the material. Rhys-Jones and Bettridge (1987) have recently proposed a review of the state of the art of this important final preparation of the airfoils, which partly determines the life time in service.

\section{Anisotropy of Mechanical Properties}

As expected from a single crystal, the mechanical behaviour of the nickel base superalloys is strongly anisotropic. This is illustrated in Fig. 10 where it can be 


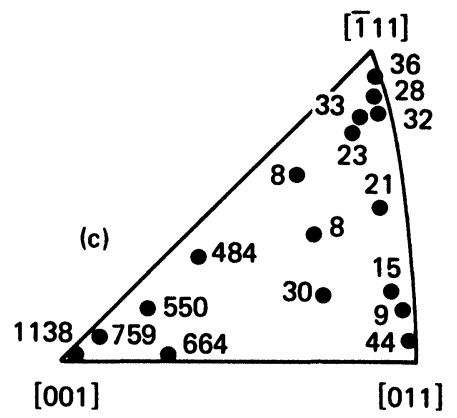

Figure 10 Stress rupture life (in hours) at $760^{\circ} \mathrm{C}$ and $750 \mathrm{MPa}$ of CM SX2 single crystals as a function of their orientation reported in the stereographic triangle (by courtesy of Caron et al., 1988).

seen that the stress rupture life in uniaxial traction creep test depends on the direction of the applied stress with regard to the crystal lattice. This orientation dependance of the mechanical behaviour was shown to be related to the temperature, to the type of mechanical test (creep, fatigue, dynamic strain, etc ...) and even to the morphology of the $\gamma-\gamma^{\prime}$ mixture.

Practically this anisotropy of mechanical behaviour is not too cumbersome for uncooled turbine blades as they are stressed essentially in the $\langle 001\rangle$ directions of the single crystal. However as their geometry becomes more and more complicated, the actual orientation map of the local stresses during service becomes more and more complex. Hence it is necessary to characterize the mechanical behaviour of the material more precisely in order to improve the structure calculations.

\section{Microstructural Changes under Mechanical Stress}

At the highest service temperatures (i.e. between about $900^{\circ} \mathrm{C}$ and $1100^{\circ} \mathrm{C}$ ) the morphology of the $\gamma-\gamma^{\prime}$ microstructure is known to strongly evolve under the action of an external stress. Figure 11 shows the successive microstructures observed at different times during an uniaxial tensile creep test in the case of alloy AM1. The $\gamma^{\prime}$ precipitates rapidly elongated perpendicular to the applied load. In fact the direction of elongation depends on the sign of the misfit $\delta$ and on the sense of the stress. In the case of negative values of $\delta$, the $\gamma^{\prime}$ platelets develop perpendicular to an uniaxial tensile stress and parallel to a compressive one, the situation being inverted in the case of a positive misfit.

Different theories have been proposed in order to explain this unusual phenomena. They are generally based on the difference in the Young's moduli of the two phases, which are unfortunately difficult to measure. Although this microstructural evolution was initially considered as structural damage, at this time it is thought to be favorable, since it leads to the development of large $\gamma-\gamma^{\prime}$ interfaces to retard dislocation motion. This is assumed to account for the low secondary creep rate presented by these alloys at high temperature (see Figure $11)$.

It is thought that the efforts made to optimize the $\gamma-\gamma^{\prime}$ microstructure are in fact not so useful since this microstructure changes so rapidly in service. However it is verified that the initial microstructure still has an influence on the high 


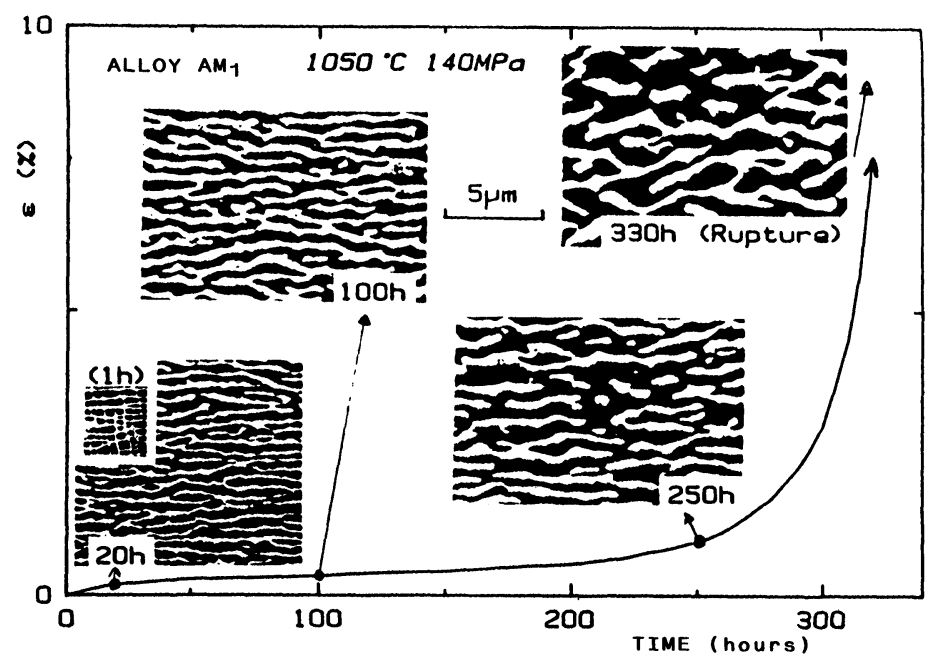

Figure 11 High temperature creep curve and associated evolution of the $\gamma^{\prime}$ morphology for alloy AM1 (by courtesy of Fredholm, 1987).

temperature creep life of the material, in a way which is not fully understood. It is advanced that the initial size distribution and spatial repartition of the precipitates determine the degree of perfection of the $\gamma-\gamma^{\prime}$ lamellae and consequently the hardening capability of the modified microstructure.

\section{CONCLUSIONS}

Although their importance is very limited in terms of produced quantity, the materials used for manufacturing the turbine blades for aircraft engines are strategic since the performances of these pieces directly limit the efficiency of the engine. Their fast development during the last decades is a good illustration of a successful collaboration between different scientific domains (fluids mechanics, process engineering, structures modelisation, materials science etc ...) owing to the impulse of a strong industrial need. This research effort led to the design of complex nickel base alloys which elaboration and manufacturing involve advanced processes and which final high temperature properties result from fine thermal and chemical treatments. At this time single crystal nickel base "superalloys" probably are the metallic materials which actually work under the hardest chemical and thermomechanical conditions. However these materials are now generally thought to have almost reached the highest level of their capabilities. As the gas inlet temperature of the next generation of aircraft engines are required to be several hundreds degrees above those of the current ones, the nickel base alloys do not seem to be appropriate for these future applications. Then research are already engaged in order to develop alternative materials (oxyde dispersion strengthened materials, ceramics, composites ...) and to readapt the design of pieces and the manufacturing processes. 


\section{References}

Bachelet, E. and Lesoult, G. (1978). Quality of Castings of Superalloys. Proceedings of a Conference held in Liège "High Temperature Alloys for Gas Turbines" Edited by Coutsouradis et al., Applied Science Publishers Ltd., pp. 665-699.

Caron, P. and Khan, T. (1983). Improvement of Creep Strength in a Nickel-base Single Crystal Superalloy by Heat Treatment. Mat. Sci. and Eng., 61, 173-184.

Caron, P., Ohta, Y., Nagakawa, Y. G., Khan, T. (1988). Creep Deformation Anisotropy in Single Crystal Superalloys. Proceedings of a Conference held in Seven Springs "Superalloys 88" Edited by Duhl et al., published by The Metallurgical Society Inc., pp 215-224.

Elliott, R. (1983). Eutectic Solidification Processing-Crystalline and Glassy Alloys. Butterworths Monographs in Metals.

Flemings, M. C. (1974). Solidification Processing. Mac Graw Hill Book Company.

Fredholm, A. (1987). Monocristaux d'Alliages Base Nickel-Relation entre Composition, Microstructure et Comportement Mécanique à Haute Température. Thesis, Ecole des Mines, Paris.

Herteman, J. P. (1985). The evolution of turbine blades materials. Matériaux et Techniques 559-556.

Kurz, W., Fisher, D. J. (1986). Fundamentals of Solidification. Trans. Tech. Publications.

Lacaze, J. (1987). Caractérisation de la Taille des Structures de Solidification Dirigée. J. Micros. Spectrosc. Electron. 12, 63-66.

McLean, M. (1983). Directionally solidified materials for high temperature service. Book $n^{\circ} 296$, The Metals Society, London.

Sellamuthu, R., Brody, H. D., Giamei, A. F. (1986). Effect of Fluid Flow and Hafnium Content on Macrosegregation in the Directional Solidification of Nickel Base Superalloys. Met. Trans. 17B, 347-356.

Sims, C. T. (1972). The Superalloys. Edited by C. T. Sims and W. C. Hagel-John Wiley Pub. New York.

Sims, C. T. (1978). High Temperature Alloys in High-Technology Systems. Proceedings of a Conference held in Liège "High Temperature Alloys for Gas Turbines" Edited by Coutsouradis et al., Applied Science Publishers Ltd., pp. 13-65.

Rhys-Jones, T. N., Bettridge, D. F. (1987). Protective Coatings for Gas Turbines. Proceedings of the First ASM Europe Technical Conference "Advanced Materials and Processing Techniques for Structural Applications", Edited by Khan T. and Lasalmonie A., ONERA, pp. 129-158.

VerSnyder, F. L. (1982). Superalloy Technology-Today and Tomorrow. Proceedings of a Conference held in Liège "High Temperature Alloys for Gas Turbines 1982 Edited by Brunetaud et al., D. Reidel Publishing Company, pp. 1-49.

Zanghi, J.-P. (1988). Les Produits Moulés en Fonderie de Précision. In Solidification des Alliages-Du Procédé à la Microstructure. Edited by Durand F., Les Editions de Physique, 55-66. 